\title{
Maternal stress or anxiety in pregnancy and emotional development of the child
}

VIVETTE GLOVER

There has been much attention paid in recent years to postnatal mental illness and also to its possible effects on the baby. Much less attention has been given to antenatal mental disorder and its possible effects on foetal development. There is increasing evidence that variations in the prenatal environment can influence the responses of the baby for life. For example, birth weight, throughout the range of low to high, has been found to be a predictor of susceptibility to coronary problems several decades later. Barker has emphasised how adult vulnerability to disease may be programmed during the foetal period (Barker, 1995). There is also increasing evidence that the foetus develops a range of behavioural responses from quite early in gestation. It responds to external sounds, for example, from at least 20 weeks (Hepper \& Shahidullah, 1994). It also can mount its own hormonal (Giannakoulopoulos et al, 1994) and other (Teixeira et al, 1996) stress responses, from at least mid-gestation.

\section{ANIMAL STUDIES}

It is clear from animal studies that the behaviour of the adult offspring can be altered by prenatal stress in the mother. In particular, the hypothalamo-pituitaryadrenal (HPA) axis has been shown to be affected, showing increased responsiveness to a particular stimulus. For example, stressing the mother monkey, by exposure to unpredictable noise during mid- to late gestation, resulted in the offspring having raised basal cortisol levels, and a raised adrenocorticotropin response during stress (Clarke et al, 1994). Similar findings have been obtained with rodents. Henry et al (1994) have shown that prenatal stress of the mother caused an elevated corticosterone response in the offspring during exposure to a novel environment. Levels of both glucocorticoid type I and type II receptors were reduced in the hippocampus at 90 days, showing a possible mechanism for the long-lasting effects on the HPA axis (Henry et al, 1994).

\section{HUMAN STUDIES}

Most human studies in this area have looked at links between a variety of types of antenatal maternal psychological distress and obstetric outcome. This is a difficult area of research, with many possible confounding variables, including genetic factors, parity, age, smoking, and so on. However, the results of several of the studies, although not all (Perkin et al, 1993), have pointed in the same direction: that antenatal maternal psychological problems are linked with complications of the pregnancy, often in a somewhat non-specific way. The most frequent findings, obtained in several independent studies, are that antenatal stress or anxiety are linked with prematurity, or low birth weight for gestational age (e.g. Pagel et al, 1990; Hedegaard et al, 1993; Copper et al, 1996).

Two studies have shown that a schedule to reduce maternal anxiety in pregnancy resulted in slightly but significantly bigger babies (Field et al, 1985; Rothberg \& Lits, 1991). However, a larger study, which used home visits, found no effect (Villar et al, 1992). More work obviously needs to be done to determine the efficacy of different types of intervention.

The best evidence for an effect of maternal stress on the development of the baby, comes from a study (Lou et al, 1994) which has examined the links between life events, or prenatal stressors, and foetal brain development. This group followed 3021 women through their pregnancy and obtained information about their stress by questionnaire. They then compared the 70 most stressed with 50 controls from the sample. They found that both antenatal stress and smoking contributed independently and significantly to a lower gesta- tional age, lower birth weight, and smaller head circumference when corrected for birth weight. Stress had a similar magnitude of effect to smoking. Prenatal stress also significantly worsened the scores on the neonatal neurological examination.

\section{POSSIBLE TRANSMISSION MECHANISMS}

The mechanism for the transmission of maternal stress to the foetus is not known. It is possible that raised maternal stress hormones constrict the uterine artery, causing impaired blood flow to the baby, which in turn generates a foetal stress response. It is also possible that, despite substantial metabolism by the placenta, certain hormones are transmitted in sufficient quantity to the foetus to have a direct effect. About $80 \%$ of maternal cortisol, which rises substantially throughout pregnancy, is metabolised to cortisone by $11 \beta$-hydroxysteroid dehydrogenase in the placenta (Tulchinsku \& Little, 1994). The only study which has looked at maternal and foetal levels together, at different gestational ages, failed to find a significant correlation (Economides et al, 1988). However, it is possible that in certain circumstances, for example, in women with reduced $11 \beta$ hydroxysteroid dehydrogenase activity, higher levels of cortisol do reach the baby.

\section{HPA RESPONSES AND DEPRESSION}

Small head circumference, one of the effects of maternal stress described by Lou et al (1994), has been linked with a later increased HPA responsiveness (Ramsay \& Lewis, 1995). This was shown by the amount of increase in saliva cortisol, after an inoculation prick, at six months of age. This, then, is similar to the effects of maternal stress found in animals.

There is substantial evidence for abnormalities of the HPA axis in many adults with major depression, including increased cortisol levels, and failure of the dexamethasone suppression test. Several groups have suggested that a hyper-responsive HPA axis is the primary defect, with changes in monoamine systems being secondary. It looks plausible that maternal stress in pregnancy has long-term neurodevelopmental effects on the infant, and these may include an increased predisposition to later depression. 


\section{CONCLUSION}

We know very little about the long-term effects of antenatal maternal stress or anxiety on the foetus, or on the child. Although there is much concern over structural teratogenic effects, there has been little attention given to possible behavioural teratogenicity. Animal studies suggest these to be quite probable. We know that the developing fetus is very sensitive to the action of certain drugs. It may well be that the developing nervous system is also affected by its hormonal milieu. Unlike other strategies to improve mental health, a programme to reduce maternal stress or anxiety during pregnancy might be relatively easy to institute. Research here could pay obvious dividends.

\section{REFERENCES}

Barker, D. J. (1995) The fetal origins of adult disease Proceedings of the Royal Society London, B Biological Sciences. 262. 37-43.

Clarke, A. S., Wittwer, D. J., Abbott, D. H., et al (1994) Long term effects of prenatal stress on HPA reactivity in juvenile rhesus monkeys. Developmentol Psychobiology. 27. 257-269.

VIVETTE GLOVER, DSc, Department of Paediatrics, Queen Charlotte's and Chelsea Hospital, Goldhawk Road. London W6 OXG

(First received 30 September 1996, revised 30 January 1997, accepted 7 February 1997)

Copper, R. L., Goldenberz, R. L., Das, A., et al (1996) The preterm prediction study: Maternal stress is associated with spontaneous preterm birth at less than thirty five weeks' gestation. Americon journal of Obstetrics and Gynecology, 175. 1286-1292.

Economides, D. L., Nicolaides, K. H., Linton, E. H., et al (19e0) Plasma cortisol and adrenocorticotropin in appropriate and small for gestational age fetuses. Fetol Theropy. 3. $158-164$.

Fildd, T., Dandberz, D., Quetal, T. A., et al (1985) Effects of ultrasound feedback on pregnancy anxiety, fetal activity, and neonatal outcome. Obstetrics and Gynaecology. 66. 525-528.

Giannakoulopoulos, X., Sepulveda, W., Kourtis, P., et of (1994) Fetal plasma cortisol and $\beta$-endorphin response to intrauterine needling. Lancet, 344, 77-81.

Hedegaard, M., Henriksen, T. B., Sabroe, S., et ol (1993) Psychological distress in pregnancy and preterm delivery. British Medical journal, 307, 234-238.

Honry, C., Kabbal, M., Simon, H., ef of (1994) Prenata stress increases the hypothalamo-pituitary-adrenal axis response in young and adult rats. Journal of Neuroendocrinology. 6. $341-345$.

Hepper, P. G. \& Shahidullah, B. S. (1994) The development of fetal hearing. Fetal and Moternal Medicine Review, 6, 167-179.
Lou, H. C., Hansen, D., Nordenfoft, M., et ol (1994) Prenatal stressors of human life affect fetal brain development. Developmental Medicine and Child Neurology, 36. 826-832.

Pagel, M. D., Smilkstein, G., Regen, H., et ol (1990) Psychosocial influences on new born outcomes: a controlled prospective study. Social Science Medicine, 30. 597-604.

Perkin, M. R., Bland, J. M., Peacock, J. L., et ol (1993) The effect of anxiety and depression during pregnancy on obstetric complications. British Journal of Obstetrics and Gynoecology, 100, 629-634.

Ramsay, D. S. Lewis, M. (1995) The effects of birth condition on infants' cortisol response to stress. Poediatrics, 95 . 546-549.

Rothbere, A. D. 2. Lits, B. (1991) Psychosocial support for maternal stress during pregnancy: Effect on birth weight. American journal of Obstetrics and Gynecology, 165. 403-407.

Teixeira, J., Fogliani, R., Giannakoulopoulos, X., et of (1996) Fetal haemodynamic stress response to invasive procedures. Lancet, 347, 624.

Tulchinaky, D. L Little, A. B. (1994) Maternal-fetal Endocrinology. Philadelphia, PA: Saunders.

Villar, J., Farnot, U., Barros, F., et ol (1992) A randomised trial of psychosocial support during high-risk pregnancies. New England journol of Medicine, 327, 1266-1271. 